\title{
ТИКОЗНЫЕ ГИПЕРКИНЕЗЫ У ДЕТЕЙ И ИХ КОМОРБИДНОСТЬ
}

\author{
*Азимова Н.М., Ачилова К.Т. \\ Ташкентский педиатрический медииинский институт, Ташкент, Узбекистан
}

В статье анализируется литература за последнее десятилетие по вопросу о тикозных гиперкинезов у детей, а также о методах их коррекции. В развитии детской неврологии был отмечен значительный прогресс в изучении этиологии, патогенеза, клинических проявлений и лечения тикозных гиперкинезов. Интерес ученых обосновала высокая частота этого заболевания в педиатрической популяции во всем мире и большое социальное значение этой проблемы. В последнее десятилетие большое внимание уделяется сопутствующим тикам когнитивным и поведенческим нарушениям. Изучение оценки когнитивной сферы, не подтвержденные объективными функциональными методами, различны и, нередко, противоречивы. В связи с этим большое значение приобретают нейрофизиологические исследования, помогающие раскрыть связи подкорковых структур и коры, дисбаланс реакций возбуждения и торможения, объективизировать клинические данные, оценить состояние когнитивных функций и эффективность лечения.

Ключевые слова: тики, тикозные гиперкинезы, когнитивные нарушения.

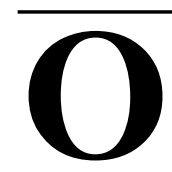
дним из проявлений патологической активности в ЦНС являются тики неожиданные, быстрые, стереотипные, повторяющиеся, неритмизированные, кратковременные, нецелесообразные движения или вокализация. Тики существенно ухудшают качество жизни больных, в периоде обострения приводят к социальной дезадаптации и нарушению обучения. Распространенность тиков среди детского населения колеблется от 4 до 24\% и преобладает у мужского пола, что обусловливает их чрезвычайную актуальность $[1,3,9]$. Наряду с широкой распространенностью, тики характеризуются упорным течением, наличием рецидивов, трансформацией в части случаев в развернутые невротические состояния, а также встречаются в виде тяжелых форм, к которым относится, в частности, синдром Жиль де ля Туретта [3]. Наибольшая частота заболевания приходится на период от 4 до 6 лет, оставаясь достаточно высокой в возрасте 7-9 лет и снижаясь до минимума к 15-16 годам $[1,4,14]$. У $7,6 \%$ больных с тиками наблюдается семейная отягощенность заболеванием [4,9]. У детей тики встречаются значительно чаще, чем у взрослых $[2,6,8]$. Среди этиологических факторов названы неблагоприятная домашняя обстановка, перемена быта (переезд), перенесенные заболевания, различные психогенные травмы [2,9]. В развитии данного страдания подчеркивается значимость роли пре- и перинатальной патологии $[1,2,4,7,9]$.
На основании клинических критериев Американская психиатрическая ассоциация выделяет три типа тикозных нарушений: 1) транзиторные; 2) хронические моторные или вокальные; 3) синдром Жиль де ля Туретта $[3,14]$. В МКБ-10 тики отнесены к блоку Г90Г98 "Эмоциональные расстройства и расстройства поведения" [7]. Возникновение тиков - сложный патогенетический процесс, в основе которого лежат не только комплекс функциональных и органических изменений, но и сбой одного из уровней сложной цепочки связей коры и подкорки с мозжечком, спинным мозгом и периферическими звеньями, а также изменения в медиаторной системе [9].

До сих пор не существует единого мнения о возникновении тиков. Решающая роль в этиологии заболевания отводится подкорковым ядрам - хвостатому ядру, бледному шару, субталамическому ядру, черной субстанции. Подкорковые структуры тесно взаимодействуют с ретикулярной формацией, таламусом, лимбической системой, полушариями мозжечка и корой лобного отдела доминантного полушария. Деятельность подкорковых структур и лобных долей регулируется нейромедиатором дофамином. Недостаточность работы дофаминергической системы приводит к нарушениям внимания, недостаточности саморегуляции и поведенческого торможения, снижению контроля двигательной активности и появлению избыточных, неконтролируемых движений $[11,13]$. 
На эффективность работы дофаминергической системы могут повлиять нарушения внутриутробного развития вследствие гипоксии, инфекции, родовой травмы или наследственная недостаточность обмена дофамина. Имеются указания на аутосомно-доминантный тип наследования; вместе с тем известно, что мальчики страдают тиками примерно в 3 раза чаще девочек. Возможно, речь идет о случаях неполной и зависимой от пола пенетрации гена $[3,10,11]$.

В большинстве случаев первому появлению у детей тиков предшествует действие внешних неблагоприятных факторов. До 64\% тиков у детей провоцируются стрессовыми ситуациями - школьной дезадаптацией, дополнительными учебными занятиями, бесконтрольными просмотрами телепередач или продолжительной работой на компьютере, конфликтами в семье и разлукой с одним из родителей, госпитализацией $[7,8,13]$.

В последнее десятилетие большое внимание уделяется сопутствующим тикам когнитивным и поведенческим нарушениям. Наиболее частым проявлением коморбидных расстройств являются ОКС (40\%), СДВГ (39\%) и их сочетание (20\%), а также тревога, страхи, депрессия, асоциальное поведение [4,8]. Трудности в учебе испытывают 60-70\% таких больных $[5,16]$.

Тики нередко возникают у детей с уже имеющимися заболеваниями со стороны центральной нервной системы (ЦНС), такими как синдром дефицита внимания с гиперактивностью (СДВГ), церебрастенический синдром, а также тревожные расстройства, включающие генерализованное тревожное расстройство, специфичные фобии и обсессивнокомпульсивное расстройство $[3,19]$.

Примерно у 11\% детей с СДВГ встречаются тики. Преимущественно это простые моторные и вокальные тики с хроническим рецидивирующим течением и благоприятным прогнозом. В отдельных случаях затруднен дифференциальный диагноз между СДВГ и синдромом Туретта, когда гиперактивность и импульсивность появляются у ребенка до развития гиперкинезов [12,15].
У детей, страдающих генерализованным тревожным расстройством или специфичными фобиями, тики могут быть спровоцированы или усилены волнениями и переживаниями, непривычной обстановкой, длительным ожиданием какого-либо события и сопутствующим нарастанием психоэмоционального напряжения [8,9].

У детей с обсессивно-компульсивными расстройствами голосовые и моторные тики сочетаются с навязчивым повторением какого-либо движения или занятия. По всей видимости, у детей с тревожными расстройствами тики являются дополнительной, хотя и патологической формой психомоторной разрядки, способом успокоения и "переработки" накопившегося внутреннего дискомфорта [17].

Церебрастенический синдром в детском возрасте является следствием перенесенных черепно-мозговых травм или нейроинфекций. Появление или усиление тиков у детей с церебрастеническим синдромом нередко провоцируется внешними факторами: жарой, духотой, изменением барометрического давления. Характерно нарастание тиков при утомлении, после длительных или повторных соматических и инфекционных заболеваний, увеличении учебных нагрузок [5,18].

Чаще всего отмечались простые моторные тики с локализацией преимущественно в мышцах лица и шеи и простые вокальные тики, имитирующие физиологические действия (кашель, отхаркивание). Подпрыгивания и сложные вокальные высказывания встречались гораздо реже - только у детей с синдромом Туретта. Временные (транзиторные) тики продолжительностью менее 1 года наблюдались чаще, чем хронические (ремиттирующие или стационарные) $[3,11,19]$.

Изучение оценки когнитивной сферы, не подтвержденные объективными функциональными методами, различны и, нередко, противоречивы [5,14]. В связи с этим большое значение приобретают нейрофизиологические исследования, помогающие раскрыть связи подкорковых структур и коры, дисбаланс реакций возбуждения и торможения [17], объективизировать клинические данные [13], 
оценить состояние когнитивных функций [1] и эффективность лечения [3].

С современных позиций нейрофизиологии, состояние нервной системы больных тиками детей характеризует преобладание процессов возбуждения над торможением. Слабость тормозных механизмов, возможно, ведет к образованию очагов застойного возбуждения в ЦНС, что является типовым патологическим процессом при многих заболеваниях нервной системы [3,5]. "Органический фон" в виде минимальной неврологической симптоматики длительное время может быть вполне компенсированным и порой даже не выявляться в силу высокой пластичности мозга ребенка. Но под влиянием неблагоприятных факторов (инфекционные заболевания, острые или хронические эмоциональные стрессы) возможны нарушение компенсации и возобновление гиперкинезов. Таким образом, не противопоставляя функциональное (психогенное) и органическое начала в патогенезе заболевания, можно констатировать лишь превалирование одного из факторов $[14,17]$.

Основным принципом терапии тиков у детей является комплексный и дифференцированный подход к лечению. До назначения медикаментозной или иной терапии необходимо выяснить возможные причины возникновения заболевания и обсудить с родителями способы педагогической коррекции. Необходимо разъяснить непроизвольный характер гиперкинезов, невозможность контроля их усилием воли и, как следствие этого, недопустимость замечаний ребенку по поводу тиков. Нередко выраженность тиков снижается при уменьшении требований к ребенку со стороны родителей, отсутствии фиксации внимания на его недостатках, восприятии его личности в целом, без вычленения "хороших" и "плохих" качеств. Терапевтический эффект оказывают упорядочение режима, занятия спортом, особенно на свежем воздухе. При подозрении на индуцированные тики необходима помощь психотерапевта, поскольку подобные гиперкинезы снимаются внушением $[12,13,16]$.

При решении вопроса о назначении медикаментозного лечения необходимо учитывать такие факторы, как этиология, возраст пациента, тяжесть и выраженность тиков, их характер, сопутствующие заболевания. Медикаментозное лечение необходимо проводить при тяжелых, выраженных, упорных тиках, сочетающихся с нарушениями поведения, неуспеваемостью в школе, влияющих на самочувствие ребенка, осложняющих его адаптацию в коллективе, ограничивающих его возможности самореализации. Лекарственная терапия не должна назначаться, если тики беспокоят только родителей, но не нарушают нормальную активность ребенка $[6,7,11]$.

Основная группа препаратов, назначаемая при тиках, - нейролептики: галоперидол, пимозид, флуфеназин, тиаприд, рисперидон. Их эффективность при лечении гиперкинезов достигает 80\%. Препараты обладают анальгезирующим, притивосудорожным, антигистаминным, противорвот-ным, нейролептическим, антипсихотическим, седативным действиями. $\mathrm{K}$ механизмам их действия относятся блокада постсинаптических дофаминергических рецепторов лимбической системы, гипоталамуса, триггерной зоны рвотного рефлекса, экстрапирамидной системы, торможение обратного захвата дофамина пресинаптической мембраной и последующего депонирования, а также блокада адренорецепторов ретикулярной формации головного мозга. Побочные эффекты: головная боль, сонливость, нарушения концентрации внимания, сухость во рту, повышение аппетита, возбуждение, беспокойство, тревога, страх. При длительном применении могут развиться экстрапирамидные нарушения, включающие повышение мышечного тонуса, тремор, акинезии $[10,11]$.

При выборе препарата для лечения ребенка с тиками следует учитывать наиболее удобную для дозирования форму выпуска. Оптимальными для титрования и последующего лечения в детском возрасте являются капельные формы (галоперидол, рисперидон), позволяющие наиболее точно подобрать поддерживающую дозу и избежать неоправданной передозировки лекарства, что особенно актуально при проведении длительных кур- 
сов лечения. Предпочтение также отдается препаратам, обладающим относительно низким риском развития побочных эффектов (рисперидон, тиаприд) [8,9].

Для лечения гиперкинезов в последние годы применяют препараты вальпроевой кислоты. Основной механизм действия вальпроатов заключается в усилении синтеза и высвобождении ?-аминомасляной кислоты, которая является тормозным медиатором ЦНС. Вальпроаты являются препаратами первого выбора при лечении эпилепсии, однако интерес представляет их тимолептический эффект, проявляющийся в уменьшении гиперактивности, агрессивности, раздражительности, а также положительное влияние на выраженность гиперкинезов. Терапевтическая доза, рекомендуемая для лечения гиперкинезов, значительно ниже, чем при лечении эпилепсии, и составляет 20 мг/кг/сут. Из побочных эффектов отмечены сонливость, повышение массы тела, выпадение волос $[3,7,10]$.

При сочетании гиперкинезов с обсессивнокомпульсивным расстройством положительный эффект оказывают антидепрессанты кломипрамин, флуоксетин [6].

Общим для всех видов тиков является соблюдение определенного режима. Следует по возможности исключить необычные и резко выраженные раздражители, как отрицательные, так и положительные. Отмечено также, что тики значительно усиливаются во время просмотра телевизионных передач, особенно в случае изменения освещенности экрана и мелькания кадров. Это обусловлено тем, что яркий мерцающий свет обладает способностью изменять биоэлектрическую активность головного мозга. По этой причине просмотр телевизионных передач детьми с тиками должен быть максимально ограничен (до 1-1,5 часов) или (лучше) запрещен в течение 1-1,5 месяцев [11,17].

Таким детям противопоказаны компьютерные игры, к которым ребенок, подросток и даже взрослый привыкает, как алкоголик к водке.

Компьютерные игры, особенно при занятиях ими 2-3 и более часов в сутки выражено нарушают мнестические функции: снижается внимание и память, ухудшается учеба, дети становятся повышенно возбудимыми, неусидчивыми, эмоционально лабильными; их мысли в школе направлены на желание скорее добраться до "ящика" с любимыми играми. Они, подобно наркоманам, становятся рабами своего желания $[4,9,18]$.

При лечении тиков, особенно психогенных, рефлекторных и идиопатических существенную роль играет психотерапия. Среди большого разнообразия методов психотерапии, наиболее часто используется индивидуальное и коллективное внушение, в том числе во время сна, аутогенная тренировка. Широкое распространение получил метод самоконтроля, направленный на выработку общих тормозных навыков. Ребенок сознательно задерживает тики на определенный промежуток времени, который постепенно удлиняется. Однако такой психотерапевтический метод борьбы с тиками путем сознательных волевых усилий ("напряжение воли") не всегда приводит к желаемым результатам. Повышенная акцентуация внимания на тиках иногда приводит к их усилению [12].

Тикозные гиперкинезы у детей в большинстве случаев сопровождаются эмоциональноволевыми расстройствами и поведенческими нарушениями: синдромом дефицита внимания с гиперактивностью, обсессивно-компульсивным синдромом, другими коморбидными состояниями, что значительно затрудняет процесс школьной адаптации ребенка, определяет медико-социальную значимость проблемы и актуальность исследования патогенеза данной патологии $[8,12,15]$.

Такого рода комбинированный подход может оцениваться как весьма перспективный и эффективный, особенно для объективизации влияния терапии.

Важность введения новых методов лечения тиков связана и с тем, что общепринятое применение нейролептиков при этом заболевании часто вызывает осложнения экстрапирамидного и гипоталамического характера. Кроме того, возникает необходимость коррекции когнитивных расстройств у данной 
категории больных. Существующее положение определяет поиск эффективных комбинированных методик.

Таким образом, широкое распространение

\section{ЛИТЕРАТУРА}

1. Биологическая обратная связь в лечении тиков /Чутко Л.С., Сурушкина С.Ю., Анисимова Т.И., Никишена И.С., Яковенко Е.А., Айтбеков К.А., Черная Ж.В. // Тезисы докладов Научно-практической конференции "Вопросы поведенческой неврологии". СПб., 2009. C.55-57.

2. Гетерогенность клинических проявлений синдрома дефицита внимания с гиперактивностью. /Чутко Л.С., Сурушкина С.Ю., Никишена И.С., Яковенко Е.А., Анисимова Т.И., Айтбеков К.А., Черная Ж.В. //Тезисы докладов Научно-практической конференции "Вопросы поведенческой неврологии". СПб., 2009. С. 57-59.

3. Зыков, В.П. Нейроиммунные аспекты патогенеза синдрома Туретта и опыт применения иммуноглобулинов у детей / В.П. Зыков, А.Ю. Щербина, Е.Б. Новикова, Т.В. Швабрина // Журн. неврол. и психиатр, им. С.С. Корсакова. - 2008. - №8. - С. 10-13.

4. Исаев, Д.Н. Психосоматическая медицина детского возраста. - М., 1991. - С. 49-51.

5. Использование цветового теста Люшера для оценки эмоционального состояния детей с тикозными гиперкинезами /ЕВ Левитина, М И Колчанова// Материалы IV терапевтического форума "Актуальные вопросы диагностики, лечения и профилактики наиболее распространенных заболеваний внутренних органов" -Тюмень. 2005 - С 42-43

6. Исследование эффективности кортексина и пантогама при коррекции когнитивных расстройств у детей с гиперкинетическим синдромом /М И Колчанова, ОР Наговицина // Человек и лекарство тезисы докладов XIV Российского национального конгресса - Москва, 16-20 апреля 2007 - Москва, 2007 - С 704

7. Клинико-нейрофизиологические особенности течения тикозных гиперкинезов в детском возрасте /МИ Колчанова, Е В Левитина // Мед наука и образование Урала-2004 -№3-4 -с 130-131

8. Левин, О.С. Тикозные гиперкинезы. Руководство по лечению и диагностике [Под ред. В.Н. Штока, И. А. Ивановой- Смоленской. - М" 2002. - С. 313-325, 327355. тиков среди детского населения и высокая резистентность к традиционным методам лечения являются причиной поиска новых подходов к терапии.

9. Опыт использования адаптола в лечении тикозных гиперкинезов у детей /Чутко Л.С., Сурушкина С.Ю., Яковенко Е.А., Никишена И.С., Анисимова Т.И., Ливинская А.М., Айтбеков К.А. //Журнал неврологии и психиатрии им. С.С. Корсакова. 2009. № 10. С. 34-45.

10. Попонникова, Т. В. Тикозные гиперкинезы у детей: патогенез, диагно стика, лечение : методические рекомендации / Т. В. Попонникова, И. Ф. Федо сеева, Г. Ю. Галиева. - Кемерово : Кузбассвузиздат, 2009. - 27 с.

11. Федосеева, И. Ф. Состояние метаболизма нейромедиаторов при тикозных гиперкинезах у детей / И. Ф. Федосеева, Т. В. Попонникова, А. В. Веремеев // Мать и дитя в Кузбассе. - 2012. - № 2. - С. 53-56.

12. Чутко, Л. С. Лечение синдрома дефицита внимания с коморбидными тикозными гиперкинезами / Л.С. Чутко, С.Ю. Сурушкина, И.С. Никишина и др. //Журн. неврол. и психиатр, им. С.С. Корсакова. - 2008. - №2. C. 66-68.

13. Штульман, Д.Р. Тики /Д.Р. Штульман, О.С. Левин / Справочник практического врача по неврологии. M., 1999.- C. 250-254.

14. American Psychiatric Association. Diagnostic and statistical manual of mental disorders 4lh ed. - Washington (DC): American Psychiatric Association, 1994.

15. Berardelli, A. Patophysiology of tics and Tourette syndrome / A. Berardelli, A. Curra et al.// J. Neurology. 2003. - Vol. 250. - P. 781-787.

16. Castillo, M.L. Sydenham's chorea: MRI and proton spectroscopy / M. Castillo, L. Kwock, A. Arbelaez // Neuroradiology. - 1999. - Vol. 41. - P. 943-945.

17. Church, A.J. et al. Anti-basal ganglia antibodies in acute and persistent Sydenham's chorea // Neurology. 2002 (2 of 2). - P. 227-231.

18. Jancovic, J. Tics and Tourette's Syndrome / In: [E. Tolosa, W.C.Coller, O.S.Gershanik (Eds)] Differential Diagnosis and treatment of movement disorders. Butterworth- Heinemann,1998. - P. 99-107.

19. Kurlan, R. Handbook of Tourette's Syndrome and Related Tic and Behavioral Disorders (Neurological Disease and Therapy). - 2005. - P. 325-329. 


\title{
XÜLASə
}

\section{USAQLARDA TIKOZ HIPERKINEZLOR VЭ ONLARIN KOMORBIDLIYİ}

\author{
Azimova N.M., Açilova K.T. \\ Daşkənt pediatrik tibb institutu, Daşkənt, Özbəkistan
}

Təqdim edilmiş məqalədə son onillikdə uşaqlarda tikoz hiperkinezlər və onların korreksiyası haqda ədəbiyyatlar araşdırılmışdır. Uşaq nevrologiyasının inkişafı ərzində tikoz hiperkinezlərin etiologiyası, patogenezi, klinik əlamətləri və müalicəsinin öyrənilməsində əhəmiyyətli irəliləyişlər əldə edilmişdir. Alimlərin bu sahəyə marağını həmin xəstəliyin bütün dünyada pediatrik populyasiyada yüksək tezliyi və bu problemin böyük sosial əhəmiyyəti əsaslandırmışdır. Son onilliklərdə tikləri müşaiyət edən koqnitiv və davranış pozulmalarına böyük diqqət ayrılır. Koqnitiv sferanın qiymətləndirilməsinin obyektiv funksional metodlarla təsdiq edilməyən tədqiqi müxtəlifdir və bəzi hallarda bir-birinə əks nəticələr alınır. Buna görə də qabıqaltı strukturlarla qabığın əlaqələrini, oyanma və tormozlanma reaksiyalarının disbalansını aşkarlamağa, klinik göstəriciləri obyektivləşdirməyə, koqnitiv funksiyaların vəziyyətini və müalicənin effektivliyini qiymətləndirməyə imkan yaradan nerofizioloji metodların əhəmiyyəti get-gedə artır.

Açar sözlər: tiklər, tikoz hiperkinezlər, koqnitiv pozulmalar.

\section{SUMMARY}

\section{TIC HYPERKINESIAS IN CHILDREN AND THEIR COMORBIDITY}

\author{
Azimova N.M., Achilova K.T. \\ Tashkent Pediatric Medical Institute, Tashkent, Uzbekistan
}

This article analyzes the literature over the past decade on the issue of tic hyperkinesias at children, and methods of their correction. The development of child neurology was marked by significant progress in the study of etiology, pathogenesis, clinical manifestations and treatment of tic hyperkinesias interest of scientists justified the high incidence of this disease in the pediatric population of the world and a great social importance. In the last decade, much attention is paid to the attendant ticks cognitive and behavioral disorders. The results of evaluation of cognition, not confirmed by the objective functional methods are different, and often contradictory. In this regard, great importance attaches to the neurophysiological studies that help to reveal the relation of subcortical structures and cortical responses imbalance of excitation and inhibition, to objectify clinical data to assess the state of cognitive functions and the effectiveness of treatment.

Key words: ticks, tic hyperkinesias, cognitive impairment.

Redaksiyaya daxil olub: 29.08.2016

Çapa tövsiya olunub: 12.09.2016

Rayçi: t.ü.f.d. X.I.H.Hasənov 